\title{
Autonomia da criança hospitalizada frente aos procedimentos: crenças da enfermeira pediatra*
}

\author{
Children's autonomy during therapeutic procedures: Pediatric nurses' beliefs and actions
}

Autonomía del niño hospitalizado frente a los procedimientos: creencias de la enfermera pediátrica

\section{Thatiana Fernanda Coa', Myriam Aparecida Mandetta Pettengill ${ }^{2}$}

\begin{abstract}
RESUMO
Objetivo: conhecer as crenças e ações da enfermeira pediatra em relação à autonomia da criança hospitalizada durante a realização de procedimentos terapêuticos. Métodos: estudo de abordagem qualitativa, em que foram realizadas observações e entrevistas com sete enfermeiras de um hospital público de São Paulo. Resultados: foram evidenciados dois temas que revelam as crenças de enfermeira e que fundamentam suas ações em relação à autonomia da criança hospitalizada: acreditando no potencial da criança para exercer a autonomia e considerando a criança incapaz de exercer a autonomia. Considerações finais: tem sido dada pouca oportunidade à criança para desenvolver sua autonomia. Como regra, em situações de conflito, o profissional não permite a participação da criança, permanecendo uma distância entre seu discurso e a prática.
\end{abstract}

Descritores: Autonomia pessoal; Enfermagem pediátrica; Criança hospitalizada; Bioética

\begin{abstract}
Objective: to understand pediatric nurses' beliefs and actions regarding hospitalized children's autonomy during therapeutic procedures. Methods: A qualitative approach was used to observe and interview seven nurses from a public hospital at São Paulo. Results: Content analysis revealed two themes: a child's potential to develop autonomy and a child's incapability to exercise autonomy. Final considerations: Few opportunities are given to children in order to develop their autonomy. As a rule, in conflicting situations nurses do not consider children decision-making; there is a disconnection between nurse's speech and professional practice.
\end{abstract}

Keywords: Personal autonomy; Pediatric nursing; Child, hospitalized; Bioethics

\section{RESUMEN}

Objetivo: conocer las creencias y acciones de la enfermera pediátrica en relación a la autonomía del niño hospitalizado durante la realización de procedimientos terapéuticos. Métodos: estudio de abordaje cualitativo, en el que fueron realizadas observaciones y entrevistas con siete enfermeras de un hospital público de Sao Paulo. Resultados: fueron evidenciados dos temas que revelan las creencias de la enfermera y que fundamentan sus acciones en relación a la autonomía del niño hospitalizado: acreditando en el potencial del niño para ejercer la autonomía y considerando al niño incapaz de ejercer la autonomía. Consideraciones finales: Se ha dado al niño poca oportunidad para desarrollar su autonomía. Como regla, en situaciones de conflicto, el profesional no permite la participación del niño, permaneciendo distancia entre su discurso y la práctica.

Descriptores: Autonomía personal; Enfermería pediátrica; Niño hospitalizado; Bioética

\footnotetext{
* Trabalbo de Iniciação Científica - $1^{\circ}$ lugar na Expo Enf $3^{\circ}$ Milênio na Área Curativa, ano 2005-Universidade Federal de São Paulo. 1 Aluna $4^{\circ}$ ano do Curso de Graduação em Enfermagem da Universidade Federal de São Paulo - UNIFESP - São Paulo (SP), Brasil.. Monitora da Disciplina de Enfermagem Pediátrica.

${ }^{2}$ Professora Adjunto da Disciplina de Enfermagem Pediátrica do Departamento de Enfermagem da Universidade Federal de São Paulo - UNIFESP - São Paulo (SP), Brasil.
} 


\section{INTRODUÇÃO}

O respeito ao ser humano é o princípio máximo do qual devem emanar os preceitos éticos de tudo e de todos que com este ser lidam. O respeito à autonomia do indivíduo é um dos pontos básicos em que se deve fundamentar toda a relação entre os seres humanos ${ }^{(1)}$.

Autonomia é um dos princípios da "trindade ética" beneficência, autonomia e justiça, e definida como "a capacidade de atuar com conhecimento de causa e sem coação externa". É ter o direito de auto-determinação, em que se inclui o direito ao respeito, à privacidade, bem como à informação necessária para a tomada de decisão ${ }^{(2)}$.

A criança é um ser em crescimento e desenvolvimento com particularidades e características próprias. Nasce totalmente dependente de cuidados, e passa por um processo de desenvolvimento progressivo até alcançar a completa independência na maturidade ${ }^{(3)}$.

No contexto da doença e hospitalização, a criança torna-se passiva, deprimida, assustada, rebelde, sentindose vulnerável, pois depende do adulto para sua sobrevivência e tem pouco controle sobre várias áreas de sua vida ${ }^{(3)}$.

A família, também se sente vulnerável durante a doença e hospitalização do filho, pois percebe sua autonomia ameaçada em razão das interações com a doença, a internação e a equipe de saúde ${ }^{(4)}$. Os membros da família se envolvem e se revezam para dar um maior suporte à criança, no sentido de garantir o acompanhamento dos cuidados, além de compartilharem a angústia, preocupação e conquistas dessa situação( ${ }^{(5)}$. Trata-se de um momento em que é preciso permitir que tanto a família quanto a criança sejam ativos partícipes quanto às questões relacionadas à doença que os aflige e ao respectivo tratamento ${ }^{(4)}$.

Cabe aos profissionais de saúde ajudá-los a caminhar em sentido oposto à vulnerabilidade. Para tanto, é preciso que seja dada à criança a oportunidade de participar das tomadas de decisão, para que sua autonomia seja desenvolvida gradualmente. De acordo com Piaget, a criança desenvolve o aprendizado e a autonomia em vários estágios. Por volta dos 6 aos 11 anos de idade, é capaz de operar o pensamento concreto, estendendo-o à compreensão do outro e às conseqüências de boa parte dos seus atos. $\mathrm{Na}$ adolescência, completa este amadurecimento com a capacidade de abstração. Considera-se que, a partir dos 15 anos, atinge as competências necessárias para o exercício da sua autonomia de forma plena, cabendo às pessoas envolvidas no processo de socialização da criança, ajudá-la no desenvolvimento da sua autonomia ${ }^{()}$.

$\mathrm{Na}$ literatura internacional há um crescente aumento no interesse dos profissionais da área da saúde sobre o envolvimento da criança nas tomadas de decisão acerca de tratamentos e procedimentos terapêuticos. Os autores discutem as questões éticas e morais envolvendo a tomada de decisão da criança, evidenciando que os direitos e responsabilidades que as crianças e adolescentes possuem, compõem um novo desafio aos profissionais da área da saúde ${ }^{(7-15)}$.

Porém, segundo um estudioso, as questões éticas e morais são geralmente interpretadas à luz de modelos psicológicos centrados no adulto, que marginalizam a vida moral das crianças e minimizam sua experiência como expressões de imaturidade ${ }^{(7)}$. A competência da criança para a tomada de decisões tem sido o foco central dos estudos. Há autores que recomendam o incentivo da participação da criança nestas decisões, com um número maior de razões a favor, do que contra essa prática $^{(8)}$.

A idade em que a criança se torna competente para tomar decisões tem gerado um amplo debate na literatura. Alguns autores consideram que a média ideal é de 10,6 anos, pois nessa idade já são capazes de promover sua autodeterminação ${ }^{(8)}$. Embora o adulto não permita à criança tomar decisões inapropriadas sobre sua saúde, principalmente em questões mais sérias, emerge a questão: se não é dada à criança alguma oportunidade para fazer escolhas, como poderá se tornar um adulto capaz de fazê-las ${ }^{(8)}$ ? Considerando que a enfermeira pediatra desempenha funções como defensora e educadora, é de sua responsabilidade preparar a criança e informá-la sobre o procedimento ao qual será submetida. Para tanto, deve considerar o nível de maturidade e habilidade da criança para participar na tomada de decisão, além de compartilhar essa informação com os outros profissionais de saúde. Além disso, a enfermeira deve ter respeito à integridade pessoal da criança e de sua autonomia. Desta forma, a inclusão da criança na tomada de decisão é um fator positivo para seu tratamento e desenvolvimento físico e psicológico ${ }^{(9)}$.

$\mathrm{Na}$ literatura nacional há uma lacuna de conhecimentos sobre a situação da criança no processo de tomadas de decisão quando hospitalizada. Em nossa prática observamos que, em geral, o profissional executa os procedimentos sem levar em consideração os desejos, opiniões e valores da criança doente, realizando-os de maneira impositiva, e a criança permanece em uma atitude de defesa, negando o tratamento. Além disso, é muito comum o uso da restrição de sua liberdade de expressão para a realização do procedimento.

Caso as decisões da criança tivessem algum peso na decisão final do cuidado, como seriam as atitudes dela na hora de se submeter a um procedimento? Seriam mais receptivas e se sentiriam mais responsáveis na participação da decisão compartilhada? E como a enfermeira pediatra tem trabalhado com essas questões na sua prática? Será 
que a enfermeira pediatra tem dado oportunidade à criança para expor suas escolhas durante a realização de um procedimento? E quando a criança se recusa a permitir a realização de um procedimento? Como a enfermeira reage e como fundamenta suas ações? Quais ações ela realiza para contribuir com o desenvolvimento da autonomia da criança?

Buscando respostas para esses questionamentos realizamos um estudo com o objetivo de conhecer as crenças e ações da enfermeira pediatra em relação a autonomia da criança hospitalizada frente à recusa de um procedimento intrusivo como a punção venosa ou a injeção intramuscular. Pretendemos, com esse estudo, oferecer subsídios para ampliar a compreensão da enfermeira sobre a importância de promover o desenvolvimento da autonomia da criança, principalmente quando se encontra doente e hospitalizada, tendo de se submeter a tratamentos dolorosos e, também, sensibilizála para a importância de seu papel como educadora, contribuindo para que a criança se desenvolva plenamente.

\section{MÉTODOS}

Estudo de natureza qualitativa, exploratório e descritivo, realizado em uma enfermaria de pediatria de um hospital público de ensino do Município de São Paulo. Participaram do mesmo sete enfermeiras pediatras que trabalham na citada unidade, sendo quatro delas com cinco anos ou menos de atuação na área e as demais acima de cinco anos de atuação na área.

Os dados foram coletados por meio de observação participante e entrevista semi-estruturada e individual, após aprovação pelo Comitê de Ética da instituição (CEP n. ${ }^{\circ}$ 1012/04). Para a entrevista, em um primeiro contato, as enfermeiras foram convidadas a fazer parte do estudo, sendo explicado o objetivo e, posteriormente, agendado o local, data e hora da entrevista, de acordo com as preferências. Após todos os esclarecimentos solicitávamos que assinassem o Termo de Consentimento Livre e Esclarecido. Todas as entrevistas foram gravadas com a permissão dos sujeitos e transcritas fiel e integralmente pelo pesquisador, após sua realização. Foi garantido o anonimato dos participantes, permitindo que expusessem todas suas impressões durante a vivência da experiência.

Para dar início foi utilizada a pergunta norteadora: Conte uma situação que você tenha vivido em que a criança entre 6 e 16 anos recusou-se a permitir a realização de um procedimento, como punção venosa ou injeção intramuscular. Em seguida foram abordadas outras questões conforme o transcorrer da entrevista: $\mathrm{O}$ que você pensou? O que você fez? Como se sentiu?

As observações das interações das enfermeiras com as crianças foram realizadas durante a execução de procedimentos técnicos, e dirigidas para as ações e atitudes da enfermeira, buscando identificar como a enfermeira conduz as ações em relação aos desejos, opiniões e valores da criança.

Incluímos observações das interações da enfermeira com crianças a partir de seis anos de idade, com base na teoria de Piaget, na qual a criança a partir dessa idade, já compreende o outro e as conseqüências de boa parte dos seus atos. Além disso, considera que a constituição do princípio de autonomia se desenvolve juntamente com o processo de desenvolvimento da autoconsciência ${ }^{(6)}$.

A análise dos dados, buscando a compreensão do fenômeno, foi orientada pelo passos da Análise Qualitativa de Conteúdo ${ }^{(16-17)}$. Trata-se de um processo de identificação, codificação e categorização dos padrões primários nos dados. O pesquisador procura o significado de passagens específicas ou parágrafos, e determina uma categoria apropriada. Ao final da análise, todos os dados precisam estar contemplados e representados.

\section{RESULTADOS}

A análise qualitativa de conteúdo realizada permitiu compreender que, ao se deparar com uma situação de recusa ao procedimento pela criança, a enfermeira sente, pensa e age com base em experiências anteriores, conhecimento teórico, crenças e valores profissionais.

Foram identificados dois temas que revelam as crenças da enfermeira durante a experiência, e que direcionam suas ações e seu comportamento: acreditando no potencial da criança para exercer a autonomia e considerando a criança incapaz de exercer a autonomia. No primeiro, a enfermeira considera que a criança tem o direito de participar das tomadas de decisão e a ajuda no enfrentamento da situação. No segundo, ela acredita que a criança é imatura e incapaz para tomar qualquer decisão, agindo de maneira impositiva. A seguir, é apresentada a descrição de cada tema.

\section{Acreditando no potencial da criança para exercer a autonomia}

Este tema evidencia que a enfermeira considera que a criança apresenta demandas que devem ser atendidas pelo profissional, durante a realização dos cuidados. A identificação dessas demandas vai sendo construída pela enfermeira, com base em conhecimento teórico e experiência profissional, que dão significado às suas ações, constituindo-se nas crenças e valores da enfermeira em relação à criança. Quando a enfermeira acredita que a criança precisa ser preparada para os procedimentos, deve ser ouvida em suas dúvidas, deve ser considerada em suas necessidades, têm o direito de extravasar suas emoções e que cabe à enfermeira o papel de atendê-las, ela age buscando atender essas necessidades.

Assim, vai explicando os procedimentos para a criança, 
conforme necessita realizá-lo. Ela inicia o contato conversando, explicando a necessidade de realizar o procedimento, repetindo várias vezes a explicação para que a criança entenda.

"A gente conversa, explica o por quê da medicação que ela recebe." E5

Quando a enfermeira percebe que a criança tem medo de sentir dor, e por isso rejeita o procedimento, age permitindo à criança extravasar emoções. Ela se coloca em seu lugar e acredita que a criança se sente invadida quando tem de ser submetida a um procedimento. Por isso, permite que a criança chore, reze ou negocie.

"Tem criança que tem muito medo, a gente conversa bastante, tem aquela que chora, aquela que fica rezando: Ai papai do céu..." E5

Ao se deparar com a situação de recusa da criança ao procedimento, a enfermeira acredita que é importante estar respeitando o tempo da criança, pois considera que assim há melhor aceitação, já que a criança terá um momento para pensar e se preparar adequadamente. Para a enfermeira, é importante que a criança descanse e se prepare para o procedimento.

"Eu falo pra ele: vou te dar um tempo, você pensa melhor na situação, explico pra ele." E2

Ouvindo a criança, revela que a enfermeira escuta as queixas de dor ou atenta para os motivos de recusa ao procedimento, e procura atender a criança da melhor forma possível. Compreende que, quanto maior a criança, mais entendimento ela tem sobre a importância de tomar a medicação, e que ouvir, faz parte de atender a criança nas suas necessidades.

"...às vezzes a criança fala que dói e a gente fala: aonde posso puncionar? A gente vai onde ela mostra" E1

A enfermeira reflete que há alguns anos, esses direitos não eram respeitados e a equipe não considerava a opinião da criança, em nenhum momento da internação.

"Há mais ou menos 18 anos não se respeitava o que a criança pensava, ela era a última que tinha a palavra" E3

Considerando as opiniões da criança, a enfermeira dá oportunidade para a criança opinar, escolhendo o local da punção, por exemplo. Acredita que quando atende a opinião da criança, esta permite o procedimento e é criado um vínculo de confiança.

"Se ela pede: Ai tia, não queria aqui, se tem no lugar que ela quer, vai no lugar que ela sente que vai ser melhor pra ela"E6

A enfermeira percebe que a mãe é sua aliada para dialogar com a criança e ajudá-la a compreender a importância dos procedimentos. Considera que, em razão da participação dos pais durante os procedimentos realizados com a criança, é necessário ir interagindo com os pais da criança, explicando-lhes a importância dos medicamentos, quantas vezes forem necessárias, porque isso lhes dá mais confiança.

"...a gente conversa, explica para os pais a necessidade da medicação, isso dá mais confiança..." E5

A enfermeira busca ajuda de outros profissionais, quando percebe que suas ações foram insuficientes para fazê-la compreender a necessidade do procedimento, discutindo a conduta a ser tomada com o médico ou a psicóloga.

"...se ele se nega, eu chamo o médico, chamo o psicólogo, que conversam com ele também...E2"

\section{Considerando a criança incapaz de exercer a autonomia}

Quando a enfermeira acredita que a criança é um ser imaturo para participar do tratamento, a considera incapaz, sem condições de saber o que é melhor para si mesma. Assim, realiza o procedimento sem considerar a opinião da criança, impondo-o, muitas vezes à força, por meio de restrição física. Age, desconsiderando a criança, tomando decisões sem consultá-la, ou ao menos explicar com calma o procedimento que irá realizar.

"a enfermeira entra no quarto e avisa a criança que terá que fazer uma punção. A criança começa a chorar e está muito amedrontada. A enfermeira pede ajuda da mãe, que senta a criança em seu colo e segura a mão da criança. A enfermeira diz.para a criança que se ela retirar a mão poderá se ferir. Ela não se move, mas continua chorosa. Ao terminar o procedimento, a criança chora bastante e fala para a deixarem em paz. (Nota de observação de campo - 14/01/2005).

A enfermeira, toma para si a responsabilidade pelas decisões considerando-as de sua exclusividade. Realiza o procedimento, mesmo que a criança se recuse a isso, usando a autoridade que acredita ter nessa situação, sempre com base na crença de que está realizando o melhor para a criança.

"...quando eu tenho certeza que não vou ter o objetivo, aí eu uso a minha autoridade. Eu consigo impor sem ser radical..." E7

Observa-se que a enfermeira não considera as 
necessidades da criança, como um ser em crescimento e desenvolvimento e não acredita que ela tenha capacidade para aceitar o procedimento durante a hospitalização e, por isso, não considera suas demandas.

A enfermeira informa à criança que irá puncionar a veia novamente, pois o acesso venoso havia sido perdido. A criança fica nervosa e diz que não quer fazer, que está com medo. A enfermeira diz que é necessário e que não vai ter jeito. Ela pede para uma auxiliar faz̧er a punção, enquanto segura o braço da criança. (Nota de observação de campo 14/01/2005).

Entretanto, acredita que deve impor o procedimento à criança somente em caso extremo, ou seja, quando do benefício que irá trazer à mesma.

"A gente não ta fazendo nada à toa, se a gente está forrando mais, tentando mais é porque realmente a criança precisa" E2

\section{DISCUSSÃO}

Os temas que emergiram do estudo revelam que, ao lidar com uma situação de recusa da criança a um procedimento, a enfermeira pensa e age com base em suas crenças e valores. Crenças são as lentes pelas quais vemos e agimos no mundo. São "verdades" de uma realidade subjetiva que influenciam a estrutura e o funcionamento biopsicossocial e espiritual, sendo intrinsecamente conectadas com o comportamento. Tanto as famílias, quanto o próprio paciente e a equipe, possuem suas próprias crenças que influenciam o cuidado. De acordo com o Modelo de Crenças, estas podem ser limitadoras ou facilitadoras ${ }^{(18)}$. Neste estudo, a enfermeira revela crenças facilitadoras quando considera que a criança é um ser em crescimento e desenvolvimento, percebe seus medos, expectativas e anseios diante do contexto de hospitalização e doença. Além disso, a enfermeira considera a mãe como suporte emocional para a criança e como sua aliada nas diversas situações de conflito. Acredita que a criança tem o direito de participar das tomadas de decisão que lhe dizem respeito, quando ela sente empatia pela situação da criança, aceitando suas limitações e compreendendo as razões da sua recusa, quando ouve a criança e age para ajudá-la no enfrentamento da situação. Porém, quando a enfermeira acredita que a criança é imatura e, portanto, incapaz para tomar qualquer decisão, agindo de maneira coercitiva, não interativa, não ouvindo os motivos e opiniões da criança, age baseada em crenças limitadoras, que não facilitam a participação da criança nas tomadas de decisões.

A partir dos dados das observações e das entrevistas, foi possível constatar uma dicotomia entre o discurso e a prática profissional, pois apesar da enfermeira afirmar que ouve a criança e que lhe dá chance de participar dos procedimentos, nem sempre foi verificado isso durante a realização dos mesmos. Em muitas ocasiões, a criança não foi ouvida e a realização do procedimento deu-se por meio de coerção, sob força, sem considerar a criança, forçando-a a aceitá-lo sem explicações. A prática da enfermeira em omitir informações tem sido uma constante, com a justificativa de proteger a criança. A enfermeira acredita que algumas informações podem preocupar a criança além de sua compreensão, pois não valoriza a capacidade da criança de compreender o que se passa ao seu redor, nem que precisa confiar nos adultos que a cercam, para que tenha segurança ${ }^{(8)}$. Tais crenças dificultam que a criança seja compreendida como um ser que pode e deve participar das tomadas de decisão que lhe dizem respeito. Quando a criança é colocada em uma posição inferior, ou quando é infantilizada sente-se desamparada e deprimida ${ }^{(3)}$. O que não pode ser ignorado é que sempre haverá situação de conflito, quando um procedimento é necessário e a criança o recusa. Este é o grande dilema das enfermeiras que, muitas vezes, precisam ganhar a confiança da criança e ao mesmo tempo realizar aquilo que ela não aceita. O que fazer então?

Em nossa prática, podemos realizar o que vários autores $^{(11-13)}$, têm recomendado: ouvir a criança, reconhecer o que a amedronta na situação, flexibilizar os horários de procedimentos, agir de maneira empática, considerar a criança como sujeito e não objeto. Apesar da determinação do tratamento pertencer à equipe de saúde e aos responsáveis pela criança, já que ela não sabe como decidir e nem lhe é garantido esse direito na legislação vigente no Brasil, é importante que ela seja estimulada a comunicar seus sentimentos e desejos. É unânime, entre os especialistas da área infantil ${ }^{(7-15)}$, a premissa de que a criança que é ouvida e levada em consideração estabelece uma relação de confiança com os adultos que a cercam.

Outro aspecto relevante a ser discutido, é o tempo de atuação da enfermeira na área pediátrica. A enfermeira com tempo de atuação inferior a cinco anos, revelou maior propensão para cuidar da criança, contemplandoa de maneira holística, ouvindo e dando oportunidade para fazer escolhas, mesmo em situações de conflito. Consideramos que tal fato possa ser um reflexo das mudanças que vêm ocorrendo na formação deste profissional na graduação e pós-graduação, com maior ênfase nas questões éticas e morais envolvendo o cuidado, assim como na discussão do papel profissional e sua inserção na comunidade.

\section{CONSIDERAÇÕES FINAIS}

Este estudo mostrou que a enfermeira age em relação à participação da criança durante procedimentos terapêuticos com base em crenças limitadoras, considerando a criança incapaz e, desta forma, não 
incentivando o desenvolvimento da sua autonomia. Apesar da enfermeira afirmar que acredita na importância da participação da criança, revelando crenças facilitadoras para o desenvolvimento da autonomia da criança, percebemos uma distância entre o discurso e a prática do profissional. Quando se depara com situações de conflito, o profissional age de maneira impositiva, não permitindo a participação da criança.

É preciso investir na formação profissional, desde a graduação, e principalmente por meio de educação continuada, oferecendo oportunidades para refletir sobre sua prática e avançar em termos de conhecimento e compromisso com a criança nesse novo milênio. É preciso que a enfermeira esteja sensibilizada para reconhecer os sentimentos de desconforto, culpa, medo e indignação que a criança vivencia durante a hospitalização, e agir com atenção verdadeira, permitindo e facilitando sua participação. A criança não deve ser desconsiderada pelos adultos, que acreditam poder fazer aquilo que consideram necessário, mesmo por meio do uso da força.

É necessário que a enfermeira pediatra seja uma defensora dos direitos da criança, que lhe permita participar sempre das tomadas de decisão, de maneira gradual, indo de situações menos complexas para as de maior complexidade, de acordo com sua maturidade; que ouça sua voz, a fim de conhecer seus verdadeiros desejos; e que busque meios para ajudá-la a enfrentar seus medos de maneira empática.

Há ainda muito a ser pensado, discutido e estudado sobre essa temática, a fim de instrumentalizar o profissional para prestar cuidado à criança e família contemplando todas as dimensões éticas.

\section{REFERÊNCIAS}

1. Leone C. A criança, o adolescente e a autonomia. Bioética. 1998; 6(1): 51-4.

2. Pessini L. Os princípios da bioética: breve nota histórica. In: Pessini L, Barchifontaine CP. Fundamentos da bioética. São Paulo: Paulus; 1996. p. 51-5.

3. Mathews-Simonton S. A família e a cura: o método
Simonton para famílias que enfrentam uma doença. São Paulo: Summus; 1990.

4. Pettengill MAM, Angelo M. Vulnerabilidade da família: desenvolvimento do conceito. Rev Latinoam Enfermagem. 2005; 13(6): 982-8.

5. Pinto JP, Ribeiro CA, Silva CV. Família da criança hospitalizada e suas demandas de cuidado. Acta Paul Enfermagem. 2004;17(4):450-2.

6. Piaget J. O julgamento moral na criança. São Paulo: Mestre Jou; 1977.

7. Carnevale FA. Listening authentically to youthful voices: a conception of the moral agency of children. In: Storch JL, Rodney P, Starzomski R, editors. Toward a moral horizon: nursing ethics for leadership and practice. Toronto: Pearson Prentice Hall; 2004. cap 19, p. 396-413.

8. Bricher G. Children in the hospital: issues of power and vulnerability. Pediatr Nurs. 2000; 26(3): 277-82.

9. Spencer GE. Children's competency to consent: an ethical dilemma. J Child Health Care. 2000; 4(3):117-22.

10. Orr FE. The role of the paediatric nurse in promoting paediatric right to consent. J Clin Nurs. 1999; 8(3):291-8.

11. Runeson I, Enskar K, Elander G, Hermeren G. Professionals' perceptions of childrens' participation in decision making in healthcare. J Clin Nurs. 2001; 10(1):708.

12. Terry L, Campbell A. Are we listening to children's views about their treatment? Br J Nurs. 2001; 10(6):384-90.

13. De Lourdes Levy M, Larcher V, Kurz R; Ethics Working Group of the Confederation of European Specialists in Paediatrics (CESP). Informed consent/assent in children. Statement of the Ethics Working Group of the Confederation of European Specialists in Paediatrics (CESP). Eur J Pediatr. 2003; 162(9): 629-33.

14. Piercy H, Hargate M. Social research on the under-16s: a consideration of the issues from a UK perspective. J Child Health Care. 2004; 8(4):253-63.

15. Beidler SM, Dickey SB. Children's competence to participate in healthcare decisions. JONAS Healthc Law Ethics Regul. 2001; 3(3):80-7.

16. Morse JM, Field PA. Qualitative research methods for health professionals. 2nd ed. Thousand Oaks, CA: Sage Publications; 1995.

17. Mayan MJ. An introduction to qualitative methods: a training module for students and professionals. Edmonton, Canada: Qualitative Institute Press; 2001.

18. Wright LM, Watson WL, Bell JM. Beliefs: the heart of healing in families and illness. New York: Basic Books; 1996. 